\section{A new role for scientists}

In an interesting discussion held in the difficult conditions of driving through the rush-hour in Geneva, L. Kowarski outlined the answers he had given to the 'anti-science brigade' at a lecture at CERN on 19 june.

Kowarski made it clear the lecture had described a new role for scientists in general, rather than physicists in particular. He began by identifying the problem as the mounting criticisms of science in the past three years, which had also been reflected in a crisis in funding. These criticisms had had the effect that the public image of science had been tarnished, that many scientists had lost their self-confidence in work, that science policy makers were more critical in their appraisals, and that the governments which funded science had reacted by limiting their support. In this, he dealt with the same problem as the Physics and Society Committee of EPS (described in their paper in the July 1972 issue). However, his suggestions for action were based on a different line of reasoning from that of the Committee.

Bearing in mind the impact on science funding of the criticisms of science, Kowarski considered that scientists had four options :

1 They could simply attempt to ignore the criticisms and carry on doing their work in the belief that the mood was just a passing phase. However, that was unlikely to be the case and it had the danger that it would only confirm the public's opinion that scientists were unresponsive, irresponsible and isolationist.

2 They could stop carrying out creative science, thus expressing their agreement with the public criticism. In Kowarski's opinion such an extreme response would be "neither logically necessary nor socially useful".

3 They could attempt to continue creative science and undertake an extra-mural role in one of the problem areas.

This way seemed to be open only to a few exceptional individuals who would have sufficient energy to contribute effectively to advances in science and to their additional task. The majority, however, would be in danger of falling between two stools.

4 The final possibility, and the one that could most naturally be recommended as the new role for scientists, was that they should blend their scientific activity with social purpose by working as scientists in the urgent areas identified by the policy makers.

The mobilisation of scientists into a new role was feasible according to Kowarski and would be reflected in a shift in funding. The tasks to which scientists would be most suited would be the diagnosis of the problems, the design of technical ameliorative measures, and the elaboration of scientifically sound arguments to be put honestly before the public. However, moving in to address specific problems would require some fundamental changes in the hitherto customary attitudes of scientists :

1 They would have to drop any claims to be the final voice in choosing their topics. Other 'experts', such as social workers, economists, science policy makers, and administrators, must be brought into the decisionmaking process.

2 The problems would not be solved by the conventional linear approach of science whereby the scientist becomes more and more concerned with single factors of a problem taken in isolation. A systems approach would be required, since generally, the aim would be to solve each urgent problem as an interdependent whole.

3 The 'hard' scientists should be willing to co-operate with their social and humanist colleagues in a spirit of mutual recognition and respect.

4 The scientists would have to come into contact with the public through discussions and the mass media.

In outlining these views, Kowarski added the reservation that care should be taken to preserve those centres of excellence where the 'flame' of advance in pure science could be carried forward. CERN was an obvious example of one possibility. However, the number of such non-mobilised scientists would be limited by their aptitude and expressed preference. In this connection, Kowarski recalled Alvin Weinberg's quip recognising the claims of the many interesting problems in pure science fields like subnuclear physics and astronomy, but questioning the need to solve them all in the lifetime of the present generation!

\section{A new North-Holland publication}

Laser

Edited by F.T. Arecchi,

Centro Informazione Studi Esperienze, Milano, Italy,

and E.O. Schulz-DuBois,

IBM Forschungslaboratorium, Zürich, Switzerland.

1972. approx. 1960 pages (2 vols.)

Dfl. $\mathbf{5 0 0 . 0 0}$ (ca. $\$ 161.00$ )

ISBN 0720402131.

(Only available as a two-volume set)

The Laser Handbook aims at presenting, in terms of encyclopaedic review, the available knowledge and experience in the established aspects of the field, as well as providing a useful contemporary survey of the more youthful areas of laser applications.

These aims clearly distinguish the Laser Handbook from the many introductory texts on the subject which have been published over the last few years.

The first volume is concerned with lasers themselves; the second volume is devoted to laser applications in the broadest sense of the word.

\section{CONTENTS :}

Part A : Basic theory and laser physics Contributors: F.T. Arecchi, V. Degiorgio, R.J. Glauber, H. Haken, L. Ronchi, M. Sargent III and M.O. Scully.

Part B : Classes of lasers

Contributors: R.B. Chesler, J.E. Geusic, H. Kressel, C.K. Rhodes, F.P. Schäfer, F. Stern and $A$. Szöke.

Part C: Laser devices and techniques Contributors: R.T. Denton, J.P. Goldsborough, P.G. Kriukov, V.S. Letokhov, H.F. Mahlein, O.P. McDuff, H. Melchior, E. Ritter, D. Roess R.G. Smith and $O$. Svelto.

Part D : Materials for nonlinear optics Contributors: S.K. Kurtz, D.A. Pinnow, W.J. Tabor and S.H. Wemple.

\section{Part E : Physical applications}

Contributors: S.A. Akhmanov, E. Courtens, H.Z. Cummins, W. Kaiser, R.V. Khokhlov, D.A. Kleinman, O.N. Krokhin, M. Maier. A. Mooradian, P.E. Schoen, A.P. Sukhorukov A. Mooradian,

Part F : Technical applications Contributors: N.G. Basov, M.I. Cohen, W.H. Culver, E.V. Hoversten, K.S. Pennington, R.V. Pole, D.E. Rounds, B. Shah, G.V. Sklizhov, A. Sona, M.L. Stitch and J.-C. Viénot.

\section{NORTH HOLLAND}

P.O. Box 1270 - Amsterdam - The Netherlands Sole distributors for the U.S.A. and Canada : American Elsevier Publishing Company, Inc. 